\title{
Research on the Online Classroom Management System in Colleges and Universities
}

\author{
Jianhong Wei \\ East China Jiao Tong University, Polytechnic Institute, Nanchang, Jiangxi, 330100
}

Keywords: Colleges and Universities; Online Classroom; Management System

\begin{abstract}
With the rapid development of modern science and technology, the application of the network in all walks of life is more common, more and more colleges and universities through the network platform to establish an online classroom. Through the network online classroom way, it not only teach students knowledge, but also impart knowledge to working staff to give more people the opportunity to learn knowledge and methods. This paper analyzes the construction of online classrooms in colleges and universities, and puts forward some suggestions on the establishment of the online classroom management system.
\end{abstract}

\section{Introduction}

The traditional learning model, subject to time and space constraints, makes some want to improve their ability, academic level of serving staff because of lack of time, resulting in unable to complete to improve their goals. In today's online age, through the application of network technology in electronic technology, changes in the traditional model of time and space constraints, learning time and place will become free up, so that practitioners can achieve their own knowledge of learning ideas but this kind of teaching model also has some problems.

\section{The Construction of Online Classrooms in Colleges and Universities}

With the development of online classroom, more and more network platform followed, such as: Tencent, Mu class, Erya knowledge and so on. Major colleges and universities have launched their own courses in a variety of network platform.

The Meaning of the Online Classroom. Compared with the traditional school classroom, online class has more subjectivity and freedom. In the teaching structure are the same, the need for teachers to "teach" and students "learning". Teachers through the network platform to broadcast the way to the students to impart knowledge, or the network platform to teachers to teach the video uploaded to the site for students to watch, or teachers through the school professor and network platform synchronized live way lectures, which are embodiment of the online classroom. Therefore, the online classroom is based on the Internet network platform as a carrier, through the students to watch the teaching process, so as to obtain knowledge of the classroom. The motivation of learning is subjective and the learning process is free.

The Current Problems in Using of Online Classroom. Curriculum model selection lacks autonomy. Colleges and universities in the teaching documents and teaching materials, etc. uploaded to the network platform, often without screening, all the information are sent to the learners, did not provide learners the opportunity to choose, so that online class for all learners have no choice, no difference between the one-way spoon-fed teaching. It cannot meet the online classroom learning effect and learning objectives, deviated from the original intention of the establishment of online class. There is no choice of uploading materials and materials may also make the learners on the course of resentment, lost interest in this course of study.

It lack of communication in the teaching process. In the online classroom mode of teacher live teaching, students can inquire about their teachers by barrage or message, and teachers can answer the questions quickly. However, most of today's online class is taken to play the teacher lectures in 
the form of video to teach students to teach. Although the teaching platform to provide a message for students to learn the questions are raised, but the teacher often cannot be answered in real time, after the answer, there may be new questions, and then again asked. This way cannot make the students questioned in real time to answer and it may miss the best opportunity for students to think. At the same time, compared with the traditional teaching, teachers can be in the classroom through the expression of students, action observation to judge their own knowledge points to explain the situation and the students understand the situation. In the online classroom, due to the lack of teachers and students face to face communication and you cannot guarantee the teaching effect, may lead to learning process less effective.

Network platform optimization is poor. Although the Internet technology has entered a new era, but the various teaching platform in the site optimization is far behind this era. With the site of teaching materials, lesson plans to download poorly optimized, resulting in very slow download. At the same time, due to poor server site optimization, once the number of users logged in more, video playback is easy to appear Caton phenomenon. On the other hand, the site in the production of the page, is still lagging behind this era, has been adapted to other pages of the page users, the learning platform for the poor view of the page. The above factors together, due to poor network platform optimization reasons, may lead to poor experience of the user experience, even if there are excellent courses, cannot restore this group of lost users.

Video frequency is low. The construction of a website is not a day of work, teaching video upload cannot be achieved overnight. Colleges and universities are usually based on school teaching usually ignore the online classroom teaching content updates. Because of the lack of attention to the online classroom, there is no arrangement for the management of the online classroom, resulting in the network platform to play the teaching video is often more old, teaching materials are not updated for a long time, including teaching ideas, teaching ideas, teaching content and so cannot keep up with the development of the times, with the actual changes and changes. Colleges and universities in the online platform to play such online video, on the one hand, is not conducive to student learning, but also easy to make students aware of these knowledge points and thinking and actual development of the deviation, misunderstanding; the other hand, students aware of the colleges and universities in the online classroom to arrange to play the video is not the latest, most likely feel despised, that the university "do not go heart", resulting in college resentment, disgust, not conducive to students self-learning, but also damage. The social image of colleges and universities, the development of individual students and the development of colleges and universities are harmless and harmless.

\section{The Recommendations for Establishment of Online Classroom Management System}

Provide a Variety of Models of Curriculum Teaching. Colleges and universities in the upload learning materials and learning video at the same time should set up a classification system, to be classified. Students will be able to more clearly understand the learning content and the corresponding teaching materials, information, choose to watch and download. At the same time, the establishment of classroom teaching video playback, live teaching lectures and other options, a number of teachers, so that students can according to their own needs to choose. This can enrich the teaching content of the online classroom, classify the teaching materials, is helpful to the students' access and can improve the students' autonomous learning ability and promote the students' enthusiasm for learning.

Improve the Teaching Communication System. The network platform should improve the communication system of the online classroom, so that all the students who have the questions and ideas will put their own questions and ideas, and publish them into the system, and the students who are studying on the platform will communicate and discuss with each other. At the same time, the development of a specific time to publish, by the teachers to question the students to answer, as much as possible to expand the students thinking space, improve student communication skills, but also to promote students interest in the course. At the same time, after the end of the course to carry out the knowledge point review, by the university to summarize the knowledge points, so that the 
professor of the course more clear, so as to achieve the purpose of improving teaching efficiency.

Optimize the Network Platform Server System. According to the current number of users using the site to increase the server capacity, making video playback, user login sites and other acts more smoothly. Optimize the page and keep up with the trend of the times, according to hot changes to change the page push content, the production of web pages, to the site users a better sense of experience. The website should set up the resource management module of the website for the learning resources, classify the learning resources according to the curriculum requirements and the teaching objectives, at the same time, improve the downlink speed of the website, set up different resource nodes and download methods, so that users can choose to download the actual situation Node and download method, on the one hand to improve the download speed, enhance the user experience, on the other hand also reflects the people-oriented thinking.

Improve the Importance of Online Classroom and Arrange a Dedicated Management Staff. As a result of scientific and technological progress, access to knowledge has been not limited to school learning, the school adhering to the concept of teaching and educating people, should pay attention to the importance of online classroom, so that more people can learn knowledge. Therefore, the school should ask the professional management of the network platform in their own colleges and universities online classroom module management. It will be the latest teacher lectures video, lectures to upload information to improve students' enthusiasm for lectures, and promote the construction of online classrooms.

\section{Conclusion}

The establishment of online classrooms in colleges and universities has become an important way to acquire knowledge at present. More and more people are starting to learn and improve themselves by watching online classroom video. Therefore, we should establish a variety of models of curriculum teaching options, improve the teaching communication system, the network platform server optimization, improve the importance of online classroom, arrange special management personnel to manage the way to build a university online classroom management system which can be conducive to the development of a variety of learning methods, but also conducive to the rise of online class, for more people who want to learn knowledge to provide learning platform and protection, so as to promote the improvement of the level of social knowledge and enhance Chinese comprehensive national strength.

\section{Acknowledgements}

Fund Project: Research on the Online Classroom Management System in Colleges and Universities.

\section{References}

[1] Sun Rong.Study on online support environment of college flip school based on whistle [J]. China Education Information, 2016, 08: 15-19.

[2] Chen Zhiwei, Tang Dongmei, Zhang Zhi. Online classroom management tools in the teaching application of colleges and universities - to class as an example [J]. Computer fans, 2016, 06: 96.

[3] Qu Xu Sheng. Effects of large-scale open online courses on classroom teaching in domestic colleges and universities[J]. Journal of Changchun Education College, 2014, 02: 105-106. 